\title{
Community mental health and concepts of mental illness in the Sundarban Delta of West Bengal, India
}

\section{Citation}

Chowdhury, A. N., A. K. Chakraborty, and Mitchell G. Weiss. 2001. “Community Mental Health and Concepts of Mental Illness in the Sundarban Delta of West Bengal, India." In Anthropology \& Medicine 8, no. 1: 109-129. doi:10.1080/13648470120063924.

\section{Published Version}

doi:10.1080/13648470120063924

\section{Permanent link}

http://nrs.harvard.edu/urn-3:HUL.InstRepos:34864849

\section{Terms of Use}

This article was downloaded from Harvard University's DASH repository, and is made available under the terms and conditions applicable to Other Posted Material, as set forth at http:// nrs.harvard.edu/urn-3:HUL.InstRepos:dash.current.terms-of-use\#LAA

\section{Share Your Story}

The Harvard community has made this article openly available.

Please share how this access benefits you. Submit a story.

\section{Accessibility}




\title{
Community Mental Health and Concepts of Mental IIIness in the Sundarban Delta of West Bengal, India
}

\author{
A.N. Chowdhury', A.K. Chakraborty ${ }^{2}$, and M.G. Weiss ${ }^{3}$
}

Submitted for publication in Anthropology and Medicine,

Special issue on Cultural Epidemiology

April 2001

Correspondence to:

Dr. A.N. Chowdhury

Institute of Psychiatry

7, D. L. Khan Road

Calcutta - 700025

INDIA

E-mail: anc@cal.vsnl.net.in

${ }^{1}$ Professor \& Head, Department of Psychiatry, Institute of Postgraduate Medical Education \& Research, Calcutta, India.

${ }^{2}$ Assistant Chief Medical Officer of Health, Diamond Harbour Subdivision, South 24 Parganas, West Bengal, India.

${ }^{3}$ Professor \& Head, Department of Public Health and Epidemiology, Swiss Tropical Institute and University of Basel, Switzerland. 


\section{Abstract :}

The Sundarban delta of West Bengal is a remote, rural region with poor infrastructure and until recently without designated mental health services or a community mental health program. To inform development of such a programme for the region, and to complement epidemiological study of rates of suicide, nonfatal deliberate self-harm, and specific psychiatric disorders, cultural epidemiological research was undertaken. This research aimed to clarify the nature of broadly conceived mental health problems in the community (not just professionally defined psychiatric disorders) and local concepts of mental illness, clarifying specific features, perceived causes, and ideas about help seeking for these problems. Findings from ethnographic study of 3 villages of 2 Sundarban blocks (Sagar and Gosaba) are presented and discussed, focussing on particular stresses and supports in the community, local priority of mental health concerns, and concepts of mental illness. This first phase of research has been followed by a cultural epidemiological survey in phase 2, studying mental illnessrelated experience, meaning, and behaviour among (1) patients coming for treatment with selected mental disorders, (2) patients admitted after surviving an episode of deliberate selfharm, (3) nonaffected laypersons in the community, and (4) health care providers with diverse orientations and credentials serving the community. As important as they are, psychiatric epidemiological data alone are insufficent to clarify the nature of needs and to specify the character of services. This research shows how cultural epidemiology informs policy and action, and how similar research in other settings may contribute to the mental health of populations.

\section{Key words}

Community mental health; Cultural epidemiology; Mental health policy; EMIC; Participatory Mapping; Sundarban Delta 


\section{Community Mental Health and Concepts of Mental IIIness in the Sundarban Delta of West Bengal, India}

After more than five decades of independence, health services for the people of India are lopsided, favouring urban and neglecting rural areas. Whatever may be said about general health services, the preponderance of mental health services in urban areas is even greater. The more distant, forested, hilly, and inaccessible regions, as expected, are most neglected of all. To some degree, this reflects a general failure to invest in health and social services everywhere, but other factors, including inadequate models and information needed to guide population-based mental health services, contribute to the relative dearth of services and needed programmes to prevent mental illness and promote mental health in rural areas.

The Sundarban region of West Bengal, south of Calcutta in the South 24 Parganas District, is an example of a neglected rural area. The Sundarban is an active delta region of the river Hooghly and other branches of the Ganges River at their confluence in the Bay of Bengal (Figure 1). It is the largest estuary on the globe, comprising 54 islands and including $4,264 \mathrm{sq} \mathrm{km}$ of reserve forest for the protection of wildlife, primarily tigers, in addition to populated areas (Table 1). The total population of the region is approximately 2.3 million. By all measures of socioeconomic development the Sundarban region is poorly developed and under served. Its inaccessibility, poor agricultural output, constantly shifting land masses and ecological instability, lack of industry and hostile climate have made this area one of the most backward regions of the state of West Bengal. The literacy level as well as the per capita income is far lower than the State average and $42.5 \%$ of the families subsist on earnings below the poverty line (De, 1994). The transportion and communication systems are poor, including about $280 \mathrm{~km}$ of paved road and $42 \mathrm{~km}$ of rail lines. During the annual monsoon much of the region becomes inaccessible. 
Inaccessibility, travel hazards on land and water, and the distances people must travel for clinical care compromise the adequacy of health services for the entire region. Furthermore, poverty, illiteracy and cultural ideas about health and illness in the context of available services, influence the help-seeking behaviour of the local population, and many of these people depend on local, traditional means of healing for all of their health problems, including mental health problems and health care needs arising from exposure to local environmental hazards, such as tiger attacks for those who survive and snake bites; they rely less on the allopathic services of government hospitals. In recent years, however, more patients with serious mental disorders have been making the trip to metropolitan Calcutta for psychiatric care. Seeing such patients coming so far for help indicated the needs in the region, and it was recognition of these needs that motivated field visits, interactions with the community, assessment of mental health problems in the existing primary health clinics, and eventually selection of the region for developing a need-based, sustainable community mental health programme (Chowdhury et al., 1999).

The need for epidemiological data to inform mental health policy and development of services is widely appreciated. Psychiatric epidemiology helps to establish the burden of disease, relative needs, and to determine priorities and resource allocations. It also provides a means of assessing the impact of health system interventions (Jenkins, 2001). Some epidemiologists, however, have also emphasized the need to attend more carefully to countryspecific features of help seeking and local barriers to recognition and treatment of mental disorders at the national level (Wittchen, 2000). Local considerations within large countries like India, however, may also vary widely, suggesting the need to link not only global and national perspectives, but also national and local perspectives (Weiss et al., 2001a). 
Psychiatric epidemiology is primarily concerned with quantitative methods to account for the occurrence of professionally defined psychiatric disorders (Kraemer et al., 1986), but ethnographic approaches also have their value and disctinct advantages for dealing with some questions (Weisner, 1997). Cultural epidemiology provides an integrative, interdisciplinary approach to assessing mental health problems, making use of epidemiological methods and anthropological frameworks that are particularly well-suited for considering the local social and cultural features of the community, and which require attention in formulating strategies for programmes responsive to locally perceived needs. The importance of balancing psychiatric epidemiological and cultural epidemiological considerations for mental health has become a recognized priority for international health (Weiss et al., 2001b).

Cultural epidemiological research was undertaken to guide the development of services and a community mental health programme for the Sundarban region. Because access to the community by outsider professionals is a complicated matter, it was clear that an assessment had to consider not just professional priorities, but also local priorities if a programme was to have any chance of acceptance. It would be important to identify the particular mental health-related concerns among the people of the region, to characterize their experience of these problems, the ways in which they interpreted these problems for themselves and explained them to others, and characteristic behaviours that either put them at risk for such problems or which they pursued to get help. Clinical psychiatric epidemiological monitoring of mental health problems and deliberate self-harm in the primary health centres was also recognized as a necessary activity to help assess needs. This approach balanced these complementary interests in both diagnosis and the cultural and social basis of mental health problems in the community, considering local preferences for help seeking with reference to available options in the complex, pluralistic health system. Although it is recognized that instruments for research in psychiatric epidemiology may be cumbersome and unwieldy 
(Ommeren et al., 2000), and hence a concern for working in these Sundarban communities, it was anticipated that the cultural epidemiological approach would focus on concerns and concepts that were understandable and acceptable within the community. It was anticipated and hoped that by including a cultural component establishing the relevance of mental health concerns, this might also facilitate psychiatric epidemiological study.

\section{Aims and approach}

The primary objective of this study was to examine locally identified mental health problems in the community, and the experience and meaning of specific mental health problems. Research aimed to clarify these issues in the context of the local health system with reference to specific interests in developing a community mental health programme. Concepts of mental health problems were to be examined with ethnographic research in the community, and specific mental health problems of particular interest in planning a mental health programme were to be examined in a clinical cultural epidemiological study of patients, and a community survey of laypersons in the community and health care providers.

The research aimed to use findings to develop a culturally appropriate mental health service system in the Sundarban region, beginning with a monthly mental health clinic on Sagar Island, which was established during the course of the research. Inasmuch as a full analysis of the first phase of research is not yet complete, and the second phase of research with the EMIC is still underway, the purpose of this report is not to discuss details of the findings, but rather to provide an overview of experience in the ethnographic phase and to show how the ethnographic phase relates to the local adaptation of the EMIC in developing a comprehensive cultural epidemiological study. 
Ethnographic research in three villages of two development blocks in the Sundarban region-Sagar Island and Gosaba Island blocks_-examined the various aspects of the social and cultural context of life in these communities, the nature of cultural and community stressors, environmental factors, gender roles, recreational use of drugs and alcohol, and concepts of health and illness. In addition to mental health problems broadly conceived, it also inquired about the experience and meaning of mental illnesses identified in these communities and behaviour related to risk and help seeking with reference to local social supports and complex health care networks. At the outset it was recognized that government services and allopathic clinicians constituted only a small component of the existing local health system.

A second phase aimed to adapt and use the EMIC, a research instrument for cultural epidemiology, to study categories and narrative accounts of illness experience (patterns of distress), the meaning of illness (perceived causes), and behaviours related to risk and help seeking. The EMIC was adapted for studying patients suffering from common mental disorders (depression or somatoform disorders) and schizophrenia, and patients who presented for treatment after an episode of deliberate self-harm. The EMIC would also need to be adapted to study comparable mental health problems as they were understood by nonaffected persons and health care providers treating mental health problems in the community. Unlike interviews with patients in the clinic, which focussed on personal history, questions for interviews in the community referred to vignettes depicting mental health problems of particular interest.

\section{Methods}




\section{Planning Ethnographic Research}

The first phase of ethnographic research involved intensive field research in three villages of both Sagar Island and Gosaba development blocks. It also required consulting records and secondary source documents from the local government and governing councils (panchayats). At the outset in planning this phase of the research, the investigators approached leaders in each development block with the assistance of medical officers in the government health system. Meetings were arranged with the Chief Medical Officer of Health $(\mathrm{CMOH})$, the Assistant Chief Medical Officer of Health (ACMOH), and the Block Medical Officers of Health (BMOH) at three Sundarban Primary Health Centres to present the objectives and plans for the research. A discussion was held to consider the feasibility of the plan, accessibility of different blocks and villages within those blocks, and the opinions of the medical officers.

Visits to four sites were planned, including Sagar island, Kakdweep, Nimpith, and Gosaba blocks with the idea of determining which among them would be selected as research sites. Based on this visit from 2-9 January 1996, which also involved meetings and introductions to local leaders (but without commitments at that point), two blocks were selected, namely, Gosaba and Sagar Islands. The two sites complemented one another, inasmuch as Sagar was relatively more accessible, linked to the mainland by a regular ferry service, and Gosaba was more remotely situated in the Sundarban interior, burdened by a poor infrastructure and in close proximity to dangerous wildlife in the tiger reserve, which from time to time threatened the local population. Some of the villages of Gosaba also suffered from lack of basic resources, such as an adequate supply of fresh water. The three villages at each site were also chosen to represent a range of conditions with these blocks

(Table 2). 


\section{[Table 2 about here]}

\section{Developing the research agenda}

To develop the research agenda and to integrate the mental health planning pespective with other social and environmental priorities, a field research advisory group (FRAG) was organized. It included an anthropologist, environmentalist, blockmedical officers, block primary health nurse, medical officer of an NGO active in Gosaba block (Rangabelia Tagore Society), and the assistant $\mathrm{CMOH}$ from Diamond Harbour responsible for the Sundarban region. Two teams of research assistants (RAs) with master's-level training and field experience in remote sites were selected for the study, one team to work in Sagar and another team for Gosaba.

A detailed plan for the ethnographic field research was developed at a three-day workshop attended by the RAs and the FRAG, specifying the methods and the kind of information that was needed from a minimum one-month period of residence in each village. A data collection format and plan was agreed upon to facilitate collection and management of data, ensuring that these data would be in a suitable format for use of a computer-assisted qualitative data analytic software program that would facilitate analysis and reporting. Research methods and their specific use in the study were reviewed; these methods included interviews, focus group discussions, participatory observation, transect walks with key informants, and participatory mapping. Other aspects of training in preparation for the field research included sessions reviewing relevant background in social science theory and research methodologies; mental health concepts; interviewing skill, which RAs practiced in mock interviews in the course of training at the Institute of Psychiatry; a review of the demographic and environmental features of the Sundarban region, and planning of field research logistics. 
The RAs then visited the Sundarban field sites for two weeks at villages other than those designated for the research, so that they could gain pilot experience with the village survey schedule as a guide for their fieldwork. When they returned and in consultation with the FRAG, feedback from the RAs was considered to prepare the final version of the Ethnographic Village Survey Schedule that was used to guide the field research that followed in the villages (Appendix 1). Field research proceeded over a period of five months, from March through July 1998 in three villages of the two development blocks, where the RAs lived during that period. Twice monthly supervisory visits by the principal investigator, AN Chowdhury, often accompanied by one or more members of the FRAG, provided an opportunity to review experience in the field and assist the RAs.

These supervisory visits provided opportunities to clarify questions in the field, review findings over the course of the work, and ensure a consistent focus of attention on issues relevant to the study. Questions of course arose; for example, what constitutes sufficent data for sensitive issues that people were reluctant to discuss-like wife battering, gender discrimination, sexual promiscuity, drug and alcohol use, and teenage pregnancy? Training of the research assistants in general anthropology—but not medicine or specialty training in medical anthropology, apart from the training provided in the study—sometimes made it difficult for them to manage and interpret health-related data. This made the supervisory visits and the opportunity to clarify field experience especially welcome and useful.

Community reactions to the researchers were generally positive, and the interest of outsiders from Calcutta in improving local health services was appreciated. Because the ethnographic component of the research had no immediately visible service component, however, some people were annoyed by the presence of researchers and asked about the material benefits that might result from their cooperation. A few remarked that they had spoken about community problems to other researchers in the past, but the persisting lack of 
drinking water, poor transportation, and inadequate health facilities showed little or nothing had come from that. Consequently, interviewing and data collection-which for the most part transpired smoothly_-became difficult at some points.

The highly complex political structure of these villages also required considerable sensitivity, discretion, and skill on the part of the researchers to manage relations with different segments of these complex communities. When the composition of focus groups brought together antagonistic participants, the aim of the activity was sometimes derailed. Timing of individual interviews naturally had to be arranged for the convenience of respondents. More difficult, interviews with people who had survived deliberate self-harm required particular sensitivity to maintain privacy and confidentiality of the information disclosed in the course of those interviews.

RAs were required to live in the village communities they were studying, and their introduction and planning for their stay required careful consideration. Introductions were made through village leaders. A careful introduction with a clear discussion of the research objectives was important to gain cooperation and trust within each village. A house was rented for the RAs, rather than their staying somewhere as a paying guest, which would be likely to complicate relations by inadvertently motivating expectations of the host family, which might expect further financial help beyond payment for accommodations, or expect job opportunities to be forthcoming. There was also the danger of being identified in the community as someone's relative, or unwittingly becoming identified with local social and political alignments and controversies.

The villages of the Sundarban where this research was conducted are politically sensitive and occasionally volatile. People wanted to know the political affiliations of the researchers and in some instances attempted to make use of the researchers' presence for personal gains. It quickly became clear to the researchers that they required a keen sense of 
observation and a healthy skepticism before reaching conclusions about many of the issues they were studying. To proceed effectively it was necessary to balance a sense of identification and membership within the community, while also maintaining a degree of skepticism, indepdence, and distance required to proceed with the work. Working in pairs helped to achieve that.

\section{Analysis of ethnographic data}

A preliminary review of findings from the first phase of research was presented in a workshop to consider their implications, plan further analysis, and plan for the next phase of field research in phase 2 with the EMIC. Two consultants from the National Institute of Mental Health and Neuro Sciences (NIMHANS) —including an anthropologist, Prof. Jayashree Ramakrishna, and a psychiatrist engaged in other cultural epidemiological studies in India, Prof. R. Raguram—participated as consultants in that workshop in July 1998. Findings were compiled in detailed village reports following the structure of the ethnographic village survey schedule. Reports were based on debriefing the RAs and their field notes, which were translated and transcribed in a format for analysis with TextBase Beta, a software program for qualitative data analysis. Participatory maps were grouped according to themes and location, and other secondary source materials were summarized, referenced, and cited in the village reports, which were presented and discussed in the workshop.

The outcome of these discussions were initial reports, plans for further detailed analysis, and a draft of 4 EMIC interview instruments for the second phase of the study. For interviews with laypersons and health care providers, six vignettes depicting mental health problems of particular interest in planning services for the community were developed as the basis for these interviews. These conditions included depression, hysteria, schizophrenia, somatoform disorder, possession and deliberate self-harm. The selection of the conditions and 
drafts of the vignettes were throughly discussed incorporating inputs from the FRAG, the consultants from NIMHANS, the field resdearch assistants, and the investigators. These discussions informed the development of lists of categories for various sections of the EMIC, including names of the various conditions identified locally, particular symptoms and patterns of distress, perceived causes, the varieties of assistance available to those seeking help for such mental health problems, and life events.

\section{Phase 2: Research with the EMIC}

Work on drafts of the EMIC continued, and 8 research assistants and one psychiatrist research coordinator were trained to use the four different versions, including one for patients coming for outpatient treatment of designated mental health problems (depression, somatoform disorders, and schizophrenia) (EMIC-PAT), patients admitted after suicidal episode of deliberate self-harm (EMIC-DSH), laypersons without overt mental disorders in the community (EMIC-NAP), and health care providers in the community (EMIC-HCP). Each of these instruments was translated into Bengali and back-translated into English. Initial translations were completed by the PI and checked by a college teacher of Bengali language, by an anthropologist, and by a sociologist. With the benefit of their comments, the translation was reviewed word by word among the investigators and research assistants who were to conduct the interviews, and these deliberations produced a semi-final version for pilot interviews.

Further training of the RAs and pilot testing of the four versions of the EMIC proceeded at the Rudranagar Rural Hospital clinic at Sagar Island, which suggested some further revisions. The training phase was completed with 37 interviews with psychiatry outpatients in the clinic at the Institute of Psychiatry, Calcutta, and in Kulpi, a field setting approximating conditions of the research sites, with the EMIC-NAP (9 interviews) and 
EMIC-HCP (5 interviews). Kulpi is located $60 \mathrm{~km}$ south of Calcutta at the entrance to the Sundarban region. Following the conclusion of these interviews, the full research team met once again to finalize the translation of the interview forms, which were sent for printing.

Examination of interrater reliability was completed with these final forms, including 25 interviews with the EMIC-P, 21 interviews with the EMIC-NAP, and17 interviews with the EMIC-HCP. Techniques for analysing the interrater agreement of structurally similar items of the EMIC were developed, and agreement overall was good. Findings from the pilot study of interrater reliability have been presented in greater detail in another publication (Chowdhury et al., 2001).

\section{Results from ethnographic study}

\section{Nature of Stress and Support in the community}

Several issues emerged repeatedly as important stress-related concerns in particular villages. Some of these were more social and political, and others were more a matter of changing environmental conditions and disrupted ecology. In the villages of Sagar Island, particular concerns arising from threats to the social order came from alcohol use, adultery, and the influence on young people of the video parlours, which have become a more pervasive influence as a result of the availability of cash from tiger prawn seed collections and betel leaf cultivation. Other perceived threats to the social order reported by some people included intercaste and interreligious marriage, community violence, and unemployment. As in many poor communities, for some people debts and obligations to the money lender are important concerns. Gender-based cultural stressors included barrenness among women, birth of female children, and the stress imposed by obligations of a persisting dowry system. Political tensions arose from conflicts between the panchayat and alternative traditional 
systems of local village administration, corruption and nepotism. Like all agricultural communities, the threat of environmental conditions leading to crop destruction was a major concern. On Sagar and Gosaba Islands land erosion is also a serious threat in an estuary subject to flooding, and where embankments are being weakened by increased human traffic to collect tiger prawn seeds, which brings both cash and neglect of other livelihood activities. In those villages where men go on fishing expeditions for weeks at a time, the threat of storms and questions of whether they would return were also matters of serious concern.

Although many problems affect both the Sagar and Gosaba communities, there are also some distinctive features. Extended deep sea fishing voyages are frequent from Sagar, but not Gosaba. Political rivalries have almost totally disrupted the panchayat system in Gosaba, depriving residents of whatever stability the panchayat provides on Sagar, mediating familial and local disputes, and providing support from funds at their disposal. The threat of wild animals — such as tigers, crocodiles, sharks, and snakes—are a serious threat in some villages of Gosaba, especially where villagers close to the tiger reserve are frequently tempted to venture in for honey gathering and wood-cutting; except for snakes, human-animal conflicts are not a concern in Sagar. The impoverished widows who survive fatal animal attacks on their husbands are a measure of the persisting human and social cost of such human-animal conflict. The lack of drinking water is similarly a serious problem for some villages of Gosaba, like Dayapur, where women wait for hours on end so that they are ready to collect water when the eratic pumps finally bring it from a distant pumping station.

A number of local organisations provide various kinds of support to people of these Sundarban communities. These organizations include the Fishermen's Samiti (Cooperative), which makes loans available to fishermen to purchase boats and nets. The Tagore Society in Gosaba also provides loans, supports tree planting, makes seeds available for agriculture, and supports women's vocational training. Poor students may receive free coaching from 
teachers. Government loans are easily available for political supporters, and money lenders offer credit at low interest, about $4-5 \%$ on for gold ornaments they hold as collateral.

Notwithstanding the politics and conflicts, a number of examples show that villagers may also help one another, especially when financial needs arise for pressing matters such as dowry and health care. Social workers have organized local women's groups (mahila samiti). Some doctors provide free treatment or extended credit, and a Sagar youth welfare club organizes blood donation camps and camps to promote awareness of the dangers of addictive drugs. Some traditional health-care providers (including magico-religious healers known as gunin and ojha) offer free treatment for snake bites. The Rotary Club of Calcutta has also established a child education centre. The Eco-Committee of Project Tiger provides clean canals for irrigation and solar lights in the market place of some Gosaba villagers. A subbranch of the Ramakrishna mission offers low-cost housing and builds latrines and fisheries, and like some panchayats they also offer loans to farmers.

\section{General medical concerns}

Children's health was identified as a priority in all of the six vilages that were studied. Women's health and reproductive health were also included among priorities of women in Gosaba. Snake bites were a particular concern in Jhaukhali, and the adverse health impact of scarce drinking water troubled the people of Dayapur. Among respiratory dieases, apart from the usual common ailments, people of Jhaukhali and Dayapur emphasized concerns about tuberculosis, and in the latter village they explained that many people will avoid anyone known to currently have or even to have had TB, as well as their families. In Arampur, people noted that because of a relatively good water supply, they are less troubled by diarrheal diseases. (It is in fact from a pumping station near Arampur that water is pumped to Dayapur.) On Sagar Island in Beguakhali, a village where fishing is especially important, 
people identified diarrheal illness as a seasonal problem, occuring mainly in winter when the dry fish is not cooked properly. More inland in Rudranagar, diarrhea is considered more a problem in the summer.

In the two smaller villages of Sagar fevers were associated with possession, but in the Gosaba sites, fevers appear to be more typically attributed to infections and seasonal changes. Skin diseases in Sagar were often neglected, and they were considered a common problem among those who spend a lot of time in the water collecting the tiger prawn seeds. Similar accounts came from Arampur, and in Jhaukhali and Dayapur eczema and vitiligo were identified as stigmatising conditions. Snake bites in both blocks were considered more a matter that required the attention of a magico-religious healer, rather than a doctor. Although people of Sagar were more likely to refer to possession as the cause of various health problems, possession was also a recognized cause of illness in Gosaba; reports in Dayapur attributed dizziness (called "reeling") and nausea to the effects of sorcery and possession.

\section{Local health system}

The allopathic health system in both blocks is mainly a mix of government services and NGO clinics. In Sagar the block hospital is a more substantial presence for government services, and in Gosaba the Rangabelia clinic of the Tagore Society represents a more substantial presence of an NGO. At both sites there are many uncredentialled medical practitioners, frequently known locally as quack doctors. Some of them even refer to themselves by that term, which appears to have a more derisive meaning for outsiders than it does locally. One such practitioner who spoke a little English, explained, "I am doing quack practice." Nevertheless, many of these uncredentialled practitioners and the nature of the regard some people have for them indicate a sense of inferiority compared with those who have recognized training and standing as allopaths, homeopaths, or Ayurvedic practitioners. 
In addition to the few allopaths, more homeopaths, and even more uncredentialled "quack" practitioners, there are also many magico-religious healers (gunin or ojha), who serve these communities. As we found out when we initiated the study of health care providers with the EMIC-HCP interviews in phase 2, we had initially underestimated their number. As we observed their practice, it also became clear that we had also failed to appreciate how many of them routinely deal with emotional problems and common mental disorders, such as depression and anxiety, but without necessarily designating these as particular disorders or discrete medical conditions. The dynamics of somatization, usually associated with the way patients transform emotional suffering into somatic experience, may also affect the way some practitioners relate the clinical problems they encounter in their professional practice.

Until a mental health clinic was recently established in Rudranagar on Sagar Island, planned in connection with this research, government services were poorly equipped and poorly regarded in the capacity to deal with mental disorders. Patients were typically referred to Calcutta for serious mental disorders, or not treated for what might seem to be less serious or unrecognized mental disorders. Among nonallopathic local healers, a homeopath on Sagar Island near Phulbari has established a reputation and become very popular for treating mental illness. Various uncredentialled practitioners have mixed reputations for treating disorders known as "hystria" (a linguistic varient of hysteria) and also for epilepsy and childhood convulsions. Priests (Hindu pujari and Muslim maulvi) and the various gunins and ojhas are also consulted for a variety of mental health problems. The phase 2 research with the EMIC will clarify details and the opportunities for cooperation among these various practitioners within the health system at large. 


\section{Identification of mental health problems}

In response to questions about the priority of mental health, most people think of seriously disruptive behaviours and what mental health professionals identify as serious psychotic disorders. Consequently, these conditions seem remote from the health concerns of most people and are typically regarded as a matter of low priority. In Dayapur, for example, we heard that mad persons are often teased by young people, and in Jhaukhali that families often abandon such people, and they have little faith in the possibility of a cure. In Rudranagar, however, the largest population centre of the six villages and the site of the block hospital and the new mental health clinic, there was more consideration of the social nature of mental illness and speculation that mental illness may result from unemployment.

The concept of mental tension is much more pervasive, and when asked about its relationship to mental illness, some respondents distinguished mental illness from mental tension by unnatural behaviour. Others distinguished mental illness from tension by its severity, suggesting that mental tension may arise from a medical illness, either one's own, a child's or someone in the family. People discussed the whole range of stressors in the community—crop failures, breached embankments, women's fears about their husband going to the forest, and so forth—as potential sources of mental tension.

People also seemed to recongize a distinction between intense sadness as an illness and everyday sadness as a part of life that passes. Some accounts identified the more severe, problematic sadness as associated with weakness and loss of appetite, and other people suggested that people who are severely affected by it may not realize as well as neighbours how serious the problem may be. In most of the villages people recalled instances of suicide and people who had tried but failed to kill themselves, or to hurt themselves. People identified the most suicides in Rudranagar, recalling 10 in the past 5 years, but these included 2 homicides that had been called suicides. There were many more attempted suicides. In 
Beguakhali people discussed 4 suicides over the past 5 years by pesticides and hanging, as well as the culturally recognized suicide threat known as jhuki mara. On Sagar in Rudranagar and Beguakhali, jhuki mara was described as the threat to commit suicide, often by daughter's-in-law under stress from in-laws and now also among children threatening their parents. People feel that it is now more frequent, and examples showed that the threat may actually lead to suicide, either as an unintended consequence of a miscalculated gesture, or from underestimation by others of the of the lethality of the suicidal intent.

Among completed suicides, a mix of death by hanging and pesticide ingestion was also discussed in Arampur, where 12 cases since 1985 were identified. In Dayapur all 8 of the suicides noted in the past 5 years had been with pesticides. Only in Jhaukhali were there no cases of suicide that anyone the researchers spoke with could recall. Residents did recollect 7 or 8 cases in the nearby village of Pathankali, however, which they associated with the bad effects of romantic entanglements of girls attending college. In Beguakhali a 15 year-old girl had recently slashed her arm after a love affair.

Concerns about problems of drugs and alcohol varied considerably among the villages. On Sagar itself, these were less of a concern in Beguakhali, the most remote of the Sagar villages, and more of an issue in Phulbari, close to the ferry link to the mainland. Ayurvedic tonics with a high alcohol content were identified as sources of alcohol intoxication in disguise in Rudranagar. Rice beer, country liquor (chulu), ganja, and various social problems arising from them (including violence and wife-beating) were discussed more commonly in the Gosaba villages. Drugs and alcohol are considered especially serious problems in Arampur. 


\section{Local concepts of mental illness}

The study aimed to identify the various local concepts of mental illness in these communities. The names of various well-known conditions, their main features, perceived causes, reactions of family and society, approach to treatment, and anticipated outcome were all considered. This inquiry was dealing mainly with the concepts, and also in some instances with reference to known cases in the community. Accounts of local idealized categories of mental illness provide an ethnographic point of reference for analysing responses of patients and the ideas of people discussing such disorders as they affect people with these conditions depicted in vignettes, which are being used in the phase 2 studies with the EMIC.

Pagla or Pagal is a common term for madness, characterized by such an affected person talking nonsense or behaving in a hostile, aggressive manner. Various ideas about its cause included diet, possession, a traumatic shock, and smoking cannabis (ganja). People attempted to treat it in the early stages, seeking help from all available sources, gunin, ojha, homeopaths, or allopaths. If the disturbance did not quickly improve or respond to treatment, however, it was likley to be hopeless, and families were known to abandon such people. The term pagal is widely used to identify a someone considered mad, and it is recognized in much of north India. Other terms were more local, or referred to more specific conditions, a specific feature of their condition, or a particular attribution of cause. Brain short, for example was a condition attributed to mental shock, but also characterized by someone talking to himself or herself, and by irritability and bad temper. Kam pagal was the result of unahppiness with a spouse. Hystria was identified as a condition that usually affects women and which may be linked with possession. It might be recognized by clamped jaws, loss of speech, prickling sensations, fits, and loss of consciousness. A range of possession states were also well-known conditions in all six study sites. 


\section{Discussion}

\section{Experience with various research methods}

Among the different types of research methods employed in the study, focus group discussions worked especially well in sampling the views of people from different social strata. Individual interviews need to be undertaken with full appreciation of the potential diversity of responses, including some extreme opinions on any particular topic. We found that interviews with the farmers in the paddy field when they were resting were especially productive. Joining them in the fields, their workplace, seemed to indicate to the farmers a genuineness and the depth of the researchers' interest. Participatory mapping was very useful. It not only provided a product, the map, to document the deliberations, but the exercise stimulated discussion and interaction that brought out ideas less likely to emerge without the activity (Figure 2). The participatory mapping exercise with a group operates as a kind of enhanced focus group, enhanced by the mapping activity, rather than just the remarks of the discussion leader, which is the initial stimulus in typical focus group discussions. Although typically used as a method for working with groups, the mapping may also enhance individual interviews.

[Figure 2 about here]

Over the course of the research the range of considerations relevant to well-being and mental health, and to emotional distress and mental health problems of the villagers expanded. This may be expected as an effect of participatory methods brought to bear on topics of such pervasive interest. A number of social concerns in the community, not anticipated at the outset, emerged as recurring themes, such as teen-age pregnancy, the 
commercial network of snake-bite healers, and even concerns about particular crab collection techniques and other dangers of life in these villages.

\section{Sadness and mental illness}

Recognizing the priority of depression as a worldwide contributor to the overall burden of disease, this research has been particularly attentive to local concepts of sadness and how its relationship to clinical depression is understood in the community. Careful study indicated that sadness was recognised as constituting an illness in some circumstances when it was very intense and associated with other symptoms. Terms for this sadness, however, were not prominent among the local terms for mental illness that researchers endeavoured to elicit. Perhaps this was because of a miscommunication about the kind of problems the researchers were interested in when they asked about mental illness. But the concept of mental health itself may have a technical, professional quality_distinct from feeling good - that is not so well understood in many communities as clinicians and health planners might expect. Although people have ideas in mind of what they mean by mental illness, the boundaries by which they distinguish emotional distress, mental health problems, mental illness, and psychiatric disorders are embedded in expectations arising from the context and setting in which the discussion takes place.

The fact that such problems were not prominent among the disorders identified in the community does not necessarily mean such a condition is not considered serious, and even a serious medical condition. Our investigation of sadness as an illness suggested that it was. Even professional ideas about what distinguishes distress and disorder change over time, which to some extent explains the ongoing process of revision of the DSM and ICD, and which is also the basis for ongoing controversies in psychiatry about whether posttraumatic 
stress disorder is really a disorder or a normal, expected outcome in response to severe stress that should not be pathologized (Summerfield, 2001).

Summerfield also brings our attention to the fact that many of the conditions that concern mental health professionals may not have an objective existence independent of the influence of the clinical gaze of the psychiatrist or other health professional, which creates a medical meaning. In any event, this discrepancy between local recognition of intense sadness as a mental illness and its lack of priority among mental disorders specified in these communities indicates the complexity of community study of mental health problems and concepts of mental illness. These are not just matters of detached academic theorizing, but key issues in the development and implementation of relevant, responsive, sustainable mental health programmes.

\section{Contribution of cultural epidemiology to community health}

The approach to cultural epidemiology that guided this research focussed on the nature of mental health problems, the experience and meaning of concepts of mental illness, and associated behaviour that affects risk and help seeking. These are questions that were thought to be especially relevant to the information needs of planning a community mental health programme for the Sundarban region, and it was this practical objective that motivated the study. Findings from the first phase of ethnographic research indicate findings concerning the topics outlined in the village ethnographic survey schedule, included in an appendix to this report. Findings from the second phase of EMIC research will provide additional quantitative and qualitative data constituting a systematic descriptive account from patient, layperson, and healthcare provider perspectives. Such cultural epidemiological data are also expected to be useful for comparative and analytic study of these conditions. 
The ethnographic component of this research has already provided useful information that contributes to the relevance of a local programme that involves not only specialised mental health services. It is also enhancing the sensitivity and responsiveness to mental health problems in primary care, establishing awareness of mental health concerns in the broader health system that serves the community, and focussing required attention on the socical and cultural components of suicide and deliberate self-harm. Although professional expertise is required, the task also requires understanding and appreciation of the concepts and language of the community and continuing dialogue and interactions in the community through community health workers, local leaders, village panchayats, NGOs and other agents of community-based development activities. The aim is to mobilize these resources to minimize the stressors and enhance the supports that halt the progression of emotional stress to mental health problems and prevent psychiatric disorders, and to promote mental health.

This report is an account of work in progress. It responds to a need for a clear account account of the ground reality, the communities expectations and needs, and the distinctive and changing social and cultural contexts (Manson, 1997). Such an account is crucial for the development of a people-orientated community mental health programme (McMichael \& Beaglehole, 2000). It is hoped that the approach described here may also be useful to other researchers and mental health policymakers who may find the frameworks and methods of cultural epidemiology useful to ensure the development, enhance the relevance, and secure the effectiveness of community mental health activities in other areas like the Sundarban with similar needs.

\section{Acknowdgement}


$-26-$

Assistance of Salil Kumar Dutta and Sohini Banerjee in preparing this report is gratefully acknowledged. Support from the Swiss National Science Foundation, Grant \#32-51068.97, Cultural Research for Mental Health, is also gratefully acknowledged.

\section{Reference List}

Chowdhury, A.N.; Chowdhury,S. \& Chakraborty,A.(1999)Eco-stress, quality of life and mental health in Sundarban delta of India. International Journal of Medicine, 6 , pp 59-63.

Chowdhury, A.N.; Sanyal, D; Dutta, S.K.; De, R.; Banerjee, S.; Bhattacharya, K.; Palit, S.; Bhattacharya, P.; Mondal, R.K.; Weiss, M.G. (2001) Interrater reliability of the EMIC in a pilot study in West Bengal. Int Med J (Japan). International Medical Journal, 8 , pp 25-29.

De, B. (Ed.) (1994). West Bengal District Gazetteers: 24 Parganas (Swaraswati Press. Government of West Bengal, Calcutta)

Dohrenwend, B.P. \& Dohrenwend,B.S. (1974) Social and cultural influences on psychopathology. Annual Review of Psychology, 25, pp 417-452.

Jenkins, R. (2001) Making psychiatric epidemiology useful: the contribution of epidemiology to government policy. Acta Psychiatr Scand, 103, pp 2-14.

Kraemer, H.C.; Pruyn, J.P.; Gibbons,R.D.; Greenhouse,J.B.et al. (1986) Methodology in psychiatric research. Archives of General Psychiatry, 44, pp 1100-1106.

Manson, S.M. (1997) Ethnographic methods, cultural context, and mental illness : Bridging different ways of knowing and experience. Ethos, 25, pp 249-258.

McMichael, A.J. \& Beaglehole,R. (2000) The changing global context of public health. Lancet, 356, pp 495-499. 
Ommeren,M.V., Sharma,B.; Makaju,R.; Thapa,S \& Jong J.D. (2000) Limited cultural validity of the composite international diagnostic interview's probe flow chart. Transcultural Psychiatry, 37, pp 119-129.

Summerfield, D. (2001) The invention of post-traumatic stress disorder and the social usefulness of a psychiatrc category. British Medical Journal, 322, pp 95-98.

Weiss, M.G.; Isaac, M.; Parkar, S.R.; Chowdhury, A.N.; Raguram, R. (2001a) Global, National, and Local Approaches to Mental Health: Examples from India. Tropical Medicine and International Health, 6(2), pp 4-23.

Weiss, M.G.; Cohen, A.; Eisenberg, L. (2001b). Mental Health. Chapter 7, pp331-377. In: Merson M, Black B, Mills A (eds.), Introduction to International Health. Gaithersberg, MD: Aspen Publishers. 2001

Weisner,T.S. (1997) The ecocultural project of human development : Why ethnography and its findings matter. Ethos, 25, pp 177-190.

Wittchen, H. U. (2000) Epidemiological research in mental disorders; lessons for the next decade of research- the NAP Lecture 1999. Nordic Association for Psychiatric Epidemiology. Acta Psychiatrica Scandinavica, 101, pp 2-10

Working Group on Priority Setting. (2000) Priority setting for health research; lessons from developing countries. Council on Health Research for Development (COHRED), Geneva, Switzerland. Health Policy and Planning, 15, pp 130-136. 
$-28-$

Figures and Tables 
$-29-$

Figure 1. Sundarban region, West Bengal, India

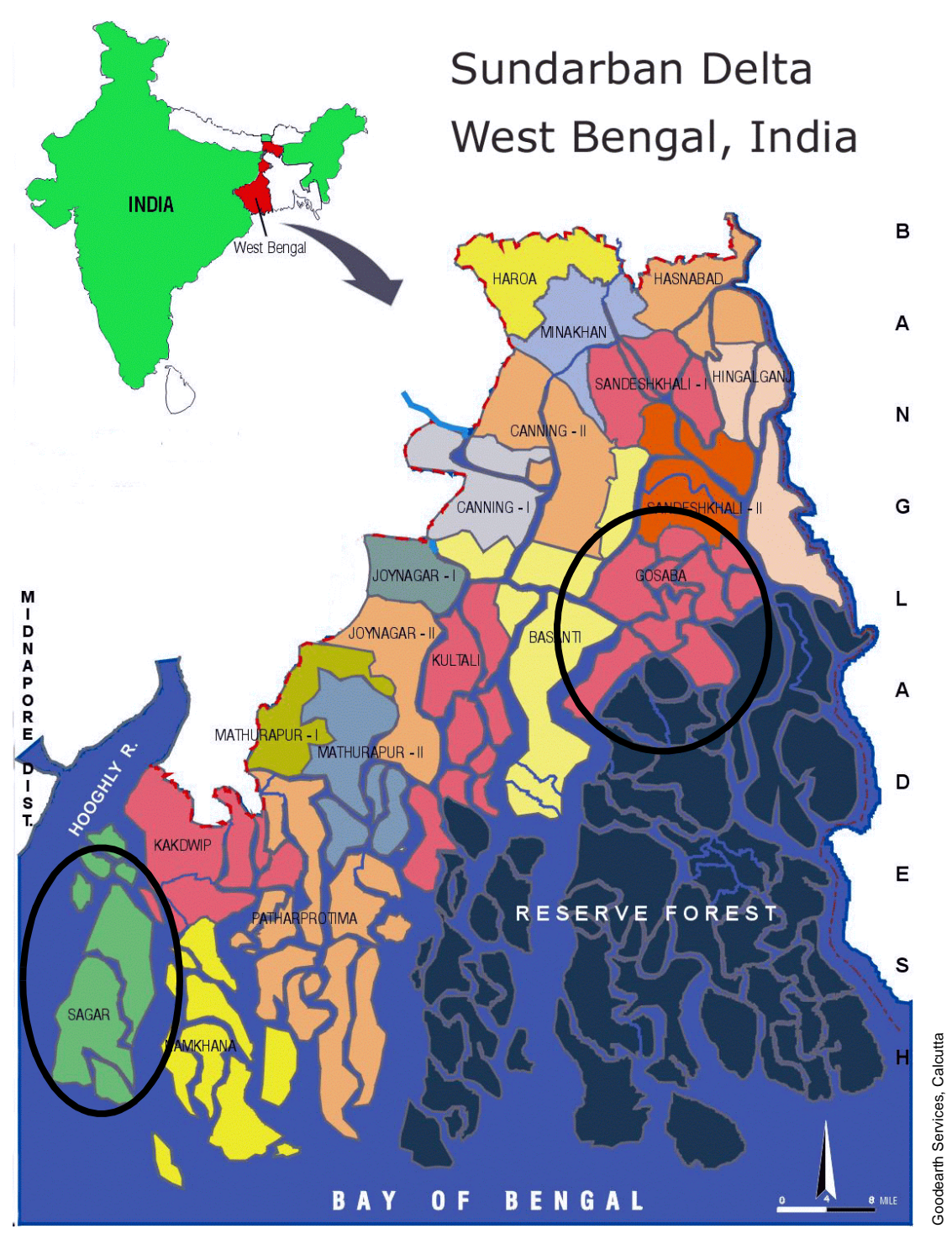


Figure 2. Participatory map of health care facilities and patient's use of one after another (Dayapur village, Gosaba Block)

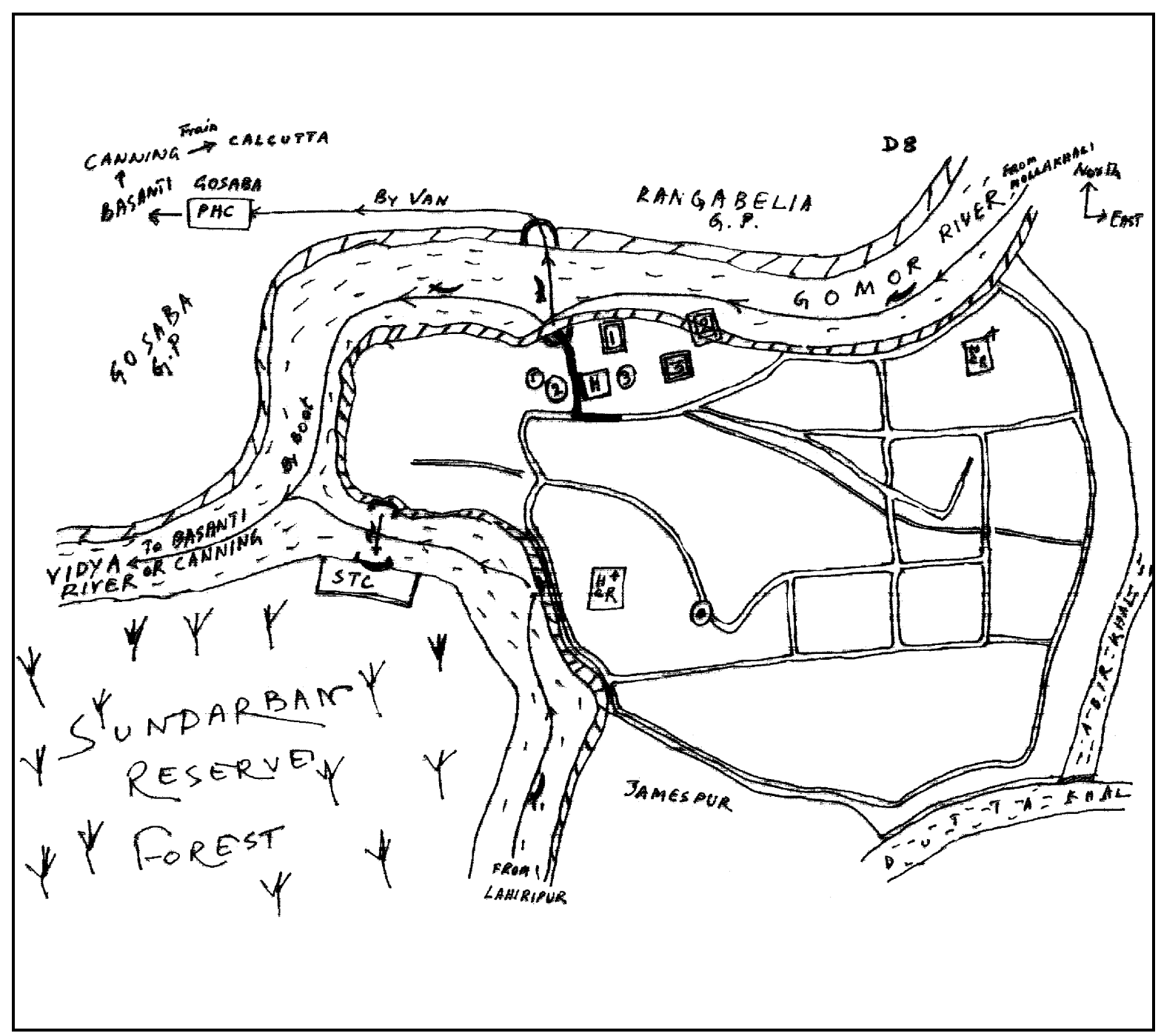

STC=Sajnakhali Tourist Centre; $\mathrm{PHC}=$ Primary Health Centre;

$\mathrm{H}=$ Government Health Subcentre; 1=Homeopath; 2=Another homeopath; 3=Allopath 
Table 1. Subdistrict administrative blocks of the Sundarban Region, South 24 Parganas District, West Bengal, India.*

\begin{tabular}{|l|r|r|r|r|r|r|r|}
\hline \multirow{2}{*}{$\begin{array}{l}\text { Administrative } \\
\text { Blocks }\end{array}$} & \multirow{2}{*}{$\begin{array}{c}\text { Area in } \\
\text { Sq Km }\end{array}$} & $\begin{array}{c}\text { Number } \\
\text { of } \\
\text { Islands }\end{array}$ & \multicolumn{1}{|c|}{ Total } & \multicolumn{1}{|c|}{ Male } & Female & $\begin{array}{c}\text { Number } \\
\text { of } \\
\text { Mouzas }\end{array}$ & $\begin{array}{c}\text { Number } \\
\text { of } \\
\text { Villages }\end{array}$ \\
\cline { 5 - 6 } Basanti & 290.0 & 2 & 226,974 & 116,425 & 110,549 & 65 & 75 \\
\hline Canning I & 205.7 & 2 & 196,295 & 100,700 & 95595 & 67 & 62 \\
\hline Canning II & 222.0 & - & 151,635 & 77,333 & 74,302 & 62 & 108 \\
\hline Gosaba & 332.5 & 11 & 200,514 & 103,286 & 97,228 & 51 & 51 \\
\hline Jaynagar I & 127.1 & - & 185,271 & 95,938 & 89,333 & 75 & 75 \\
\hline Jaynagar II & 175.2 & - & 177,335 & 91,327 & 86,008 & 45 & 209 \\
\hline Kakdweep & 261.1 & - & 190,088 & 97,563 & 92,525 & 39 & 113 \\
\hline Kultoli & 240.9 & 3 & 156450 & 80516 & 75934 & 43 & 90 \\
\hline Mathurapur I & 148.4 & - & 141,888 & 73,264 & 68,624 & 99 & 99 \\
\hline Mathurapur II & 230.5 & 1 & 172,982 & 90,177 & 82,805 & 28 & 175 \\
\hline Namkhana & 227.1 & 1 & 134,354 & 69,018 & 65,336 & 35 & 35 \\
\hline Pathar- & 469.5 & 13 & 245,601 & 125,904 & 119,697 & 87 & 94 \\
\hline pratima & 470.8 & 4 & 154,202 & 79,242 & 74,960 & 44 & 44 \\
\hline Sagar & & & & & & & \\
\hline
\end{tabular}

*Data from District Statistical Handbook. Bureau of Applied Economics \& Statistics, Government of West Bengal. Calcutta: T.T. Traders, 1998.

*Mouza is the term for sub-block divisions, which in Sagar and Gosaba blocks approximate village boundaries. 
Table 2. Sundarban village field sites for ethnographic study

\begin{tabular}{|c|c|c|c|c|c|c|}
\hline \multirow{2}{*}{ Features } & \multicolumn{3}{|c|}{ Sagar block } & \multicolumn{3}{|c|}{ Gosaba block } \\
\hline & Beguakhali & Rudranagar & Phulbari & Jhaukhali & Dayapur & Arampur \\
\hline $\begin{array}{l}\text { Rationale } \\
\text { for } \\
\text { selection }\end{array}$ & Most remote & $\begin{array}{r}\text { Most } \\
\text { populous }\end{array}$ & $\begin{array}{r}\text { Ferry } \\
\text { connection } \\
\text { to mainland }\end{array}$ & Remote & $\begin{array}{l}\text { Near tiger } \\
\text { reserve }\end{array}$ & populous \\
\hline $\begin{array}{l}\text { Population } \\
\text { (1991) }\end{array}$ & 3,950 & 5,653 & 1,031 & 1,312 & 4,735 & 5,287 \\
\hline $\begin{array}{l}\text { Literacy } \\
\text { rate } \\
\text { Male } \\
\text { Female }\end{array}$ & $\begin{array}{l}24 \% \\
30 \% \\
18 \%\end{array}$ & $\begin{array}{l}71 \% \\
81 \% \\
64 \%\end{array}$ & $\begin{array}{l}29 \% \\
36 \% \\
21 \%\end{array}$ & \multicolumn{2}{|c|}{ (Block data only) } & $\begin{array}{l}35.8 \% \\
48.7 \% \\
22.0 \%\end{array}$ \\
\hline $\begin{array}{l}\text { Main } \\
\text { economic } \\
\text { activities }\end{array}$ & $\begin{array}{r}\text { Rice, chilli, } \\
\text { betel leaf, } \\
\text { fishing, tiger } \\
\text { prawn, van } \\
\text { pulling, } \\
\text { tailoring }\end{array}$ & $\begin{array}{r}\text { Rice, betel, } \\
\text { government } \\
\& \text { private } \\
\text { services, } \\
\text { day labour, } \\
\text { van pulling, } \\
\text { trade }\end{array}$ & $\begin{array}{l}\text { Rice, betel, } \\
\text { fishing, tiger } \\
\text { prawn, day } \\
\text { labour, trade }\end{array}$ & Rice, labour & $\begin{array}{r}\text { Rice, tiger } \\
\text { prawn, chilli, } \\
\text { fishing, crab } \\
\text { collection, } \\
\text { honey } \\
\text { gathering, } \\
\text { wood-cutting }\end{array}$ & $\begin{array}{r}\text { Rice, sea } \\
\text { fishing, } \\
\text { trade, some } \\
\text { honey } \\
\text { gathering } \\
\text { and wood- } \\
\text { cutting }\end{array}$ \\
\hline Transport & Bicycle van & $\begin{array}{r}\text { Bicycle van, } \\
\text { bus }\end{array}$ & $\begin{array}{r}\text { Government } \\
\text { ferry service } \\
\text { to mainland, } \\
\text { bus, bicycle } \\
\text { van }\end{array}$ & $\begin{array}{c}\text { Small boat } \\
\text { service, } \\
\text { bicycle van }\end{array}$ & $\begin{array}{l}\text { Small boat } \\
\text { service, } \\
\text { bicycle van }\end{array}$ & $\begin{array}{r}\text { Small boat } \\
\text { service, } \\
\text { bicycle van }\end{array}$ \\
\hline $\begin{array}{l}\text { Communi- } \\
\text { cations }\end{array}$ & $\begin{array}{r}\text { No } \\
\text { telephone, } \\
\text { radio, or TV }\end{array}$ & $\begin{array}{r}\text { Telephone } \\
\text { (local and } \\
\text { STD), } \\
\text { newspaper, } \\
\text { dish antenna }\end{array}$ & $\begin{array}{r}\text { No } \\
\text { telephone, } \\
\text { radio, or TV }\end{array}$ & $\begin{array}{r}\text { Local } \\
\text { telephone, } \\
\text { sub-post } \\
\text { office, } \\
\text { newspaper, } \\
\text { FM radio \& } \\
\text { TV (solar } \\
\text { power) }\end{array}$ & $\begin{array}{r}\text { No } \\
\text { telephone; } \\
\text { sub-post } \\
\text { office, } \\
\text { newspaper, } \\
\text { FM radio \& } \\
\text { TV (solar } \\
\text { power) }\end{array}$ & $\begin{array}{r}\text { STD } \\
\text { telephone; } \\
\text { branch and } \\
\text { sub-post } \\
\text { office; } \\
\text { newspaper, } \\
\text { FM radio, TV } \\
\text { (electricity } 4 \\
\text { hrs daily) }\end{array}$ \\
\hline
\end{tabular}


Appendix 1.

\section{Ethnographic village survey schedule (Abridged summary)}

1. Approaches to data collection
a. Interviews, focus groups, and participant observation
b. Case histories, especially of people with mental health problems (considering social, economic, environmental (climate and wild life), and political stressors and supports
c. Transect walks with key informants
d. Participatory mapping, focussing on themes such as location of irritation sites and drinking water, religious places, health infrastructure and providers, dangerous places, recreational and educational places, environmental hazards and features, social tensions
e. Records and documentation from the village council (panchayat)

2. Identification of each village study site
a. Location, history of settlement, environmental features
b. Population: ethnic and caste composition
c. Economic activiites, transportation, and communication
d. Environmental features and problems (soil erosion, salinization, crop destruction, human- animal conflict)

3. Mental health and general health problems and services

a. Mental Illness in the Community

i. What are mental health problems?

(1) What are they and how are they identified?

(2) Specific features of experience, meaning, and behaviour associated with each

ii. Are they a matter of concern?

iii. Distinguishing emotional tensions, social problems, and mental illness

iv. Is sadness an illness?

v. Community reactions to mental illness

vi. Experience in the community with suicide and deliberate self-harm

b. Drug and alcohol use in the community

c. Other health priorities and problems (eg, epilepsy, leprosy, stigmatised and chronic disease)

d. Health services in the community, especially for mental health problems

i. Orientation, qualifications, and experience of local health care providers

ii. What they treat and how they treat it

iii. Cost, location, and perceived quality of care

4. Social contexts and concerns
a. Communal and political tensions
b. Social changes and responses to them; order and disorder
c. Educational opportunities within and outside the village
d. Occupational opportunities and local economy
e. Recreational Leisure activities (video parlours, community festivals)
f. Sexual promiscuity, extramarital sex, commercial sex
g. Gender
i. Social role of women in home and community
ii. Women's issues that come to panchayat
iii. Domestic violence
iv. Age and patterns of marriage

h. Childhood

i. Perceived value of education, perceived quality and distance of schools, school attendance by age 
$-34-$

ii. Child labour 